\title{
OCORRÊNCIA DE BOTULISMO EM BOVINOS CONFINADOS NO RIO GRANDE DO SUL
}

\author{
Franciele Maboni, ${ }^{1}$ Fernanda Monego, ${ }^{1}$ Iveraldo Dutra, ${ }^{2}$ Mateus Matiuzzi da Costa $^{3}$ E \\ Agueda Castagna de Vargas ${ }^{1}$ \\ 1. Universidade Federal de Santa Maria, Laboratório de Bacteriologia. Departamento de Medicina Veterinária Preventiva. \\ E-mail: franmaboni@gmail.com \\ 2. Universidade Estadual Paulista, Departamento Apoio, Produção e Saúde Animal \\ 3. Universidade do Vale do São Francisco.
}

\section{RESUMO}

Botulismo é a intoxicação causada pela neurotoxina produzida pelo Clostridium botulinum, caracterizando-se por paralisia flácida ou completa da musculatura esquelética. Este trabalho relata um surto de botulismo em bovinos confinados, alimentados com silagem de milho. Amostras de fígado, conteúdo intestinal e ruminal de um dos bovinos com o quadro clínico característico de botulismo e uma porção da silagem de milho foram encaminhados para análise bacteriológica. No laboratório realizaram-se bioensaio em camundongos e soroneutralização, sendo confirmada a suspeita de botulismo tipo C. Este relato visa alertar médicos veterinários e criadores que adotam o confinamento de animais, pois esta prática de manejo aumenta a suscetibilidade ao botulismo, principalmente relacionada ao tipo e qualidade do alimento consumido.

PALAVRAS CHAVE: Bovinos, Clostridium botulinum, confinamento.

\section{ABSTRACT}

\section{OCCURRENCE OF BOTULISM IN FEEDLOT BOVINE IN RIO GRANDE DO SUL STATE/ BRAZIL}

Botulism is the intoxication caused by a neurotoxin produced by the Clostridium botulinum, distinguished by flacid or complete skeletal musculature paralysis. This study reports a botulism outbrake in feedlot bovine, fed with corn silage. Samples of the liver, and of the intestinal and ruminal content from one of the bovine that presented typical clinical state for botulism, as well

KEYWORDS: Bovine, Clostridium botulinum, feedlot.

\section{INTRODUÇÃO}

Botulismo é uma intoxicação caracterizada pela paralisia motora rápida, ocasionada pela toxina do Clostridium botulinum, um microrganismo que prolifera em carcaças em decomposição e algumas vezes na as a portion of corn silage were sent for bacterial analysis. In the laboratory, bioassay and serum neutralization were performed on rats, confirming the suspect for type $\mathrm{C}$ botulism. This report intends to warn veterinaries and breeders, which practice herd feedlot, because this procedure increases botulism susceptibility, and it is mainly related to the type and quality of the food ingested. 
classificadas de A a G, distintas antigenicamente, mas semelhantes quanto ao modo de ação. Comumente são as toxinas $\mathrm{C}$ e $\mathrm{D}$ que acometem os ruminantes (ORTOLANI et al., 1997; DUTRA et al., 2005; LOBATO et al., 2008).

As neurotoxinas produzem paralisia funcional sem o desenvolvimento de lesões. Agem pela ligação aos receptores das terminações nervosas e, uma vez dentro dos neurônios, interferem na liberação de acetilcolina na junção neuromuscular. A toxina do $C$. botulinum tipo $\mathrm{C}$ atua clivando as duas proteínas essenciais, SNAP-25 e sintaxina, para a fusão sináptica com a membrana plasmática dos neurônios, para que haja a exocitose da acetilcolina (HUMEAU et al., 2000). Com o bloqueio desse neurotransmissor, a paralisia flácida é desencadeada e o animal morre, em virtude de parada respiratória (RADOSTITS et al., 2000).

Os sinais clínicos característicos do botulismo incluem a paralisia muscular flácida, que se inicia nos membros posteriores, progredindo para os membros anteriores e cabeça. Intranquilidade, ataxia e andar cambaleante também são relatados (COLBACHINI et al., 1999). Os membros se mantêm flácidos, e o animal é incapaz de manter a cabeça ereta, apoiando-a sobre o flanco ou permanecendo em decúbito esternal seguido de lateral (ORTOLANI et al., 1997). Ocorrem, também, midríase e perda do tônus da língua, com subsequente sialorreia (BÖHNEL et al., 2001). A paralisia dos músculos torácicos resulta na respiração abdominal terminal. Raramente, são observados casos de recuperação, o que se dá em três a quatro semanas (ORTOLANI et al., 1997).

A pecuária extensiva em regiões de solos ácidos (deficientes em minerais) expõe os animais a problemas de mineralização, de modo que eles se tornam sensíveis à intoxicação pelas toxinas de $C$. botulinum presentes em grande quantidade nesse tipo de ambiente (DUTRA et al., 2005). Nas criações extensivas, as formas mais comuns de intoxicação estão associadas à osteofagia em animais mantidos em solos deficientes principalmente em fósforo e proteínas (DUTRA et al., 2001). Dessa forma, a suplementação mineral e proteica é essencial para evitar que os animais desenvolvam vício osteofágico, como forma de suprir suas carências nutricionais (PIMENTEL, 1993).

A ingestão de água estagnada e contaminada com carcaças de animais ocasiona altos índices de mortalidade, além de aumentar a distribuição do microrganismo no ambiente (DUTRA et al., 2001). A enfermidade acomete também animais confinados, nos quais a ocorrência do botulismo está associada à presença das toxina $\mathrm{C}$ e $\mathrm{D}$ nos alimentos, como cama de frango, silagem, milho e feno (ORTOLANI et al., 1997; DUTRA et al., 2005).

Apesar de o Brasil apresentar condições favoráveis ao desenvolvimento do botulismo, ainda são poucos os relatos que demonstram a verdadeira realidade brasileira diante dessa enfermidade. No estado do Rio Grande do Sul (RS), essa situação não é diferente. A paralisia em bovinos criados em sistema de confinamento não havia sido diagnosticada e relatada anteriormente. Neste trabalho, apresenta-se um caso de intoxicação por $C$. botulinum $\mathrm{C}$ em bovinos mantidos em sistema de confinamento no RS.

\section{MATERIAL E MÉTODOS}

No município de Cachoeira do Sul, RS, em uma propriedade de criação de bovinos de corte ocorreu a morte de seis animais, sendo dois bezerros e quatro bovinos adultos. Os animais estavam recebendo silagem há setenta dias, e as mortes só tiveram início com a abertura do último dos três silos. As manifestações clínicas observadas foram condizentes com as do botulismo e os animais morreram em menos de 24 horas. Outros dois animais da propriedade desenvolveram a forma crônica da doença e se recuperaram. As mortes cessaram após a interrupção do fornecimento de silagem.

Amostras de fígado, conteúdo intestinal e ruminal e uma porção de silagem de milho desta propriedade foram encaminhadas à análise bacteriológica, no Laboratório de Bacteriologia da Universidade Federal de Santa Maria (UFSM). O fígado foi macerado, diluído com solução fisiológica 1:2, e mantido em refrigeração por um período de 12-24 horas, a fim de eluir a toxina eventualmente presente no tecido hepático. Em seguida, a suspensão foi centrifugada e o sobrenadante filtrado. O conteúdo intestinal e ruminal também foram centrifugados e filtrados para a obtenção do sobrenadante. A silagem foi adicionada em meio Cooked Meat Medium (CMM), fervida por vinte minutos e incubada por cinco dias a $37^{\circ} \mathrm{C}$ (QUINN et al., 2005). Após este período, foi processada da mes- 
ma forma que os conteúdos intestinal e ruminal. Para a avaliação da toxicidade das amostras, preconizaramse o bioensaio e soroneutralização em camundongos, a partir dos sobrenadantes, de acordo com a metodologia descrita por SEBALD \& PETIT (1997). Inocularam-se $0,5 \mathrm{~mL}$ do filtrado em camundongos via intraperitoneal. Realizou-se o cálculo da DL50 pelo método proposto por REED \& MUENCH (1938), juntamente com a verificação da toxina envolvida.

\section{RESULTADOS E DISCUSSÃO}

Os animais inoculados manifestaram sinais clínicos compatíveis com o botulismo ("cintura de vespa"), morrendo em menos de vinte horas. A titulação da toxina no conteúdo intestinal demonstrou a presença de 10 DL 50. Pela soroneutralização, detectou-se a toxina do tipo C. A presença de toxina foi confirmada pelo teste de microfixação do complemento em extrato hepático, realizada no Departamento de Apoio, Produção e Saúde Animal da Universidade Estadual Paulista Júlio de Mesquita Filho, Araçatuba (UNESP).

Segundo DUTRA et al. (2005), animais confinados são susceptíveis à intoxicação botulínica, o que se deve às condições de risco provocadas pelos alimentos. Frequentemente, silagem, feno ou ração são malconservados, com matéria orgânica em decomposição, umidade, anaerobiose, ou com cadáveres de pequenos mamíferos ou aves, que geram condições ideais para multiplicação bacteriana e produção de toxina. Neste relato, as mortes cessaram após a interrupção do fornecimento da silagem, sendo que esta apresentava sua lona de proteção com orifícios, o que gerou a presença de porções enegrecidas. Tal fato ocorre normalmente pela presença de fungos que se desenvolvem a partir das pequenas aberturas onde existe mais oxigenação, elevando a temperatura e alterando o aspecto da silagem.

Do quadro clínico observado, inicialmente, constavam dificuldade de locomoção, paralisia flácida dos membros posteriores e anteriores, decúbito lateral, dispneia, discreta salivação, respiração abdominal, progredindo para morte após 24 horas do início dos sinais. Tal quadro é caracteristicamente relatado (SIMMONS \& TAMMEMAGI, 1964; CARDOSO et al., 1994; ORTOLANI et al., 1999; RADOSTITS et al., 2000), sendo condizente com o esperado na intoxicação por $C$. botulinum. Dos animais intoxicados, dois desenvolveram a forma crônica da doença, recuperando-se. De acordo com ORTOLANI et al. (1997), estes casos são raros, mas pode ocorrer a recuperação em três a quatro semanas.

Segundo COLBACHINI et al. (1999), a detecção e a identificação da toxina botulínica em soro ou vísceras (conteúdo intestinal e ruminal, fígado, fezes) de bovinos com sinais clínicos típicos são consideradas suficientes para confirmar o diagnóstico de botulismo. Para a confirmação da atividade tóxica, o bioensaio ou teste de neutralização em camundongos foi utilizado, avaliando-se as manifestações dos camundongos, principalmente a presença da "cintura de vespa". Conforme COLBACHINI et al. (1999), o bioensaio pode ser usado para determinar a presença da toxina no soro de bovinos que recebem altas doses do inóculo tóxico e apresentam quadro clínico agudo e subagudo, sendo uma técnica bastante satisfatória (COLBACHINI et al., 1999). Outros testes já são usados, como o ensaio imunoenzimático, as técnicas moleculares, as quais detectam genes codificadores de toxinas, tendo resultados satisfatórios, principalmente pelo menor tempo de diagnóstico e detecção de frações não tóxicas (LINDSTROM \& KORKEALA, 2006).

Em bovinos existe uma grande dificuldade no diagnóstico laboratorial da doença, pois a espécie é extremamente sensível a pequenas quantidades de toxina botulínica em relação aos camundongos utilizados em bioensaio (DUTRA et al., 2001), o que pode gerar casos de falsos-negativos. Exceção se faz aos casos em que a intoxicação é superaguda e a concentração da toxina é alta (JONES, 1991), como no trabalho de intoxicação experimental realizado por COLBACHINI et al. (1999), em que o emprego do bioensaio, para a detecção da toxina botulínica em soros de bovinos inoculados com altas doses desta, mostrou-se extremamente satisfatório.

A vacinação é considerada a medida profilática mais importante contra o botulismo. Apesar disso, a proteção vacinal depende da dose ingerida da toxina, pois os animais vacinados podem desenvolver a doença quando expostos a grandes quantidades desta (LOBATO et al., 2008). Além do mais, a melhoria das condições ambientais e sanitárias com a eliminação das fontes de intoxicação e uma adequada suplementação alimentar são essenciais para a prevenção da intoxicação. A prática de apenas enterrar as carcaças não é recomendada, pois animais escavadores trazem à superfície os restos contaminados. Portanto, o ideal é removê-las, incinerá-las 
e posteriormente enterrá-las em áreas onde os demais animais não tenham acesso (PIMENTEL, 1993).

O botulismo é uma enfermidade de importante casuística, sendo que sua presença gera, na pecuária, grandes perdas econômicas. Dessa forma, este relato vem alertar os criadores e veterinários que animais em confinamentos são também susceptíveis ao botulismo, estando isso relacionado principalmente ao tipo e qualidade do alimento consumido e armazenado.

\section{REFERÊNCIAS}

BÖHNEL, H.; SCHWAGERICK B.; GESSLER, F. Visceral botulism: a new form of bovine Clostridium botulinum toxication. Journal Veterinary Medicine, v. 48, p. 373-383, 2001.

CARDOSO, A. L. M.; MINEO, J. R.; SILVA, D. A. O.; SOUZA, M. A.; COELHO, H. E.; TAKETOMI, E. A.; METIDIERI, M. A.; ROSA, M. A. Botulismo experimental em bovinos induzido pela toxina tipo D: avaliação clínica e laboratorial. Hora Veterinária, v. 78, p. 58-62, 1994.

COLBACHINI, L.; SCHOCKEN-ITURRINO, R. P.; MARQUEZ, L. C. Intoxicação experimental de bovinos com toxina botulínica tipo D. Arquivo Brasileiro de Medicina Veterinária e Zootecnia, v. 51, p. 229-234, 1999.

DUTRA, I. S.; DÖBEREINER, J.; ROSA, I. V.; SOUZA, L. A. A.; NONATO, M. Surtos de botulismo em bovinos no Brasil associado à ingestão de água contaminada. Pesquisa Veterinária Brasileira, v. 21, p. 43-48, 2001.

DUTRA, I. S.; DÖBEREINER, J.; SOUZA, A. M. Botulismo em bovinos de corte e leite alimentados com cama de frango. Pesquisa Veterinária Brasileira, v. 25, p. 115-119, 2005.
HUMEAU, Y.; DOUSSAU, F.; GRANT, N. J; POULAIN, B. How botulinum and tetanus neurotoxins block neurotransmitter release. Biochimie, v. 82, p. 427-446, 2000.

JONES, T.O. Bovine botulism. Practice, v. 13, p. 83-86, 1991.

LINDSTROM, M.; KORKEALA, H. Laboratory diagnostics of botulism. Clinical Microbiology Revision, v. 19, p. 298-314, 2006.

LOBATO, C. F.; SALVARANI, F. M.; SILVA, R. O. S.; SOUZA, A. M.; LIMA, C. G. R. D.; PIRES, P. S.; ASSIS, R. A.; AZEVEDO, E. O. Botulismo em ruminantes causado pela ingestão de cama-de-frango. Ciência Rural, n. 4, v. 38, p. 1176$1178,2008$.

ORTOLANI, L. E.; BRITO, L. A.; MORI, C. S.; SCHALCH, U.; PACHECO, J.; PIMENTEL, J. C. Botulismo. O Corte, n. 31, 1993.

QUINN, P.J.; MAEKEY, B.K.; CARTER, M.E.; DONNELLY, W.J.; LEONARD, F.C. Microbiologia veterinária e doenças infecciosas. São Paulo: Artmed, 2005. p. 94-105.

RADOSTITS, O. M.; GAY, C. C.; BLOOD, D. C; HINCHCLIFF, K. W. Veterinary medicine. 9. ed. 2000. p.757-760.

REED, L. J.; MUENCH, H. A simple method of estimating fifty per cent endpoints. American Journal of Hygiene, v. 27, p. $493-$ $497,1938$.

SIMMONS, G.C.; TAMMEMAGI, L. Clostridium botulinum type D as a cause of bovine botulism in Queensland. Australian Veterinary Journal, v. 40, p. 123-127, 1964.

SEBALD, M.; PETIT, J.C. Méthodes de laboratoire bactéries anaérobies et leur identification: deuxième édition augmentée. 2. ed. Paris: Institut Pasteur, 1997. p. 189-197. 